\title{
IMPROVEMENT OF OVERALL EQUIPMENT EFFECTIVENESS OF BARREL PRE-HONING MACHINE LINE
}

\author{
Greeshma Anup ${ }^{1}$, Pooja A.V ${ }^{2}$, M. Varsha Machaiah ${ }^{3}$, Tejas P. Govekar', A. Balakrishna ${ }^{5}$ \\ ${ }^{1}$ UG student, Department of Industrial Engineering and Management, M.S. Ramaiah Institute of Technology, \\ Bangalore-560054, India \\ ${ }^{2}$ UG student, Department of Industrial Engineering and Management, M.S. Ramaiah Institute of Technology, \\ Bangalore-560054, India \\ ${ }^{3}$ UG student, Department of Industrial Engineering and Management, M.S. Ramaiah Institute of Technology, \\ Bangalore-560054, India \\ ${ }^{4}$ UG student, Department of Industrial Engineering and Management, M.S. Ramaiah Institute of Technology, \\ Bangalore-560054, India \\ ${ }^{5}$ Associate Professor, Department of Industrial Engineering and Management, M.S. Ramaiah Institute of Technology, \\ Bangalore-560054, India
}

\begin{abstract}
Bosch Group is one of the leading global supplier of technology and services. The company was established in Stuttgart in the year 1886 by Robert Bosch a leading industrialist (1861-1942) as "Workshop for Precision Mechanics and Electrical Engineering." Bosch Limited located at Adugodi, Bangalore manufactures one of the components of the diesel engine called an Element. It is made up of the assembly of two parts called the Barrel and the Plunger. When the plunger is inserted into the barrel, it creates a pressure drop in the pump which is used to inject the fuel into the engine. This paper reports the current Overall Equipment Effectiveness (OEE) and its improvement in the Barrel Pre-honing Machine Line, which is a process involved in the manufacture of a barrel. Improvement of the OEE is beneficial to improve the productivity. The scope of the project was to collect data to calculate the current OEE and create improvements. The project undertaken involved identifying the bottleneck area and eliminating the bottleneck. To do this, the Takt time chart of the various processes involved in the manufacture of the barrel was analyzed. The bottleneck was identified to be the Pre-Honing line which consisted of 12 machines. Preliminary analysis was carried out on the Pre-Honing line of barrels to obtain the current state data for the month of January and February. Graphical analysis of the collected data showed that two machines in particular had relatively lower OEE of the 12 machines. Any improvement on these two machines would lead to increased production, eliminating the bottleneck. Hence these two machines in particular were chosen as the subject of study. Thus the project aims at reducing Availability, Performance and Quality losses of the machines using SFMC (Shop Floor Management Cycle). Shop floor management cycle is a procedural system developed by Bosch to improve the Overall Equipment Efficiency in the troublesome process and hence the production and productivity. The identification of the bottleneck is done through Takt chart and then hourly monitoring is used to identify the losses. Further this data is analyzed to obtain the root causes of the problem. These causes are subjected to critical analysis, validated and appropriate actions are taken to reduce or eliminate them. The SFMC concepts include tracking all the activities that take place in the machine line. This includes creating a Takt time chart, maintaining hourly monitoring sheet, OEE tracking, creating a Pareto chart of the losses, problem solving (Ishikawa Diagram, 5-why) and PDCA sheet. The Hone Holder Tracking Sheet was designed and implemented to reduce the availability losses due to non-availability of hone holder sets. On implementation, the OEE of the line was improved from 70 to $84 \%$.
\end{abstract}

Keywords: Bosch Limited, Overall Equipment Effectiveness, OEE, TPM, SFMC

$* * *$

\section{INTRODUCTION}

Overall Equipment Effectiveness (OEE) is a way to monitor and improve the efficiency of the manufacturing process. Overall equipment effectiveness is a hierarchy of metrics developed by Seiichi Nakajima in the 1960s to evaluate how effectively a manufacturing operation is utilized. OEE has become an accepted management tool to measure and evaluate plant floor productivity. OEE is broken down into three measuring metrics of Availability, Performance, and Quality. These metrics help gauge the plant's efficiency and effectiveness and categorize these key productivity losses that occur within the manufacturing process. OEE empowers manufacturing companies to improve their processes and in turn ensure quality, consistency, and productivity measured at the bottom line.[1].

Overall equipment effectiveness In considering OEE, Nakajima (1988) defines six large equipment losses.

1. Equipment failure/breakdown losses are categorized as time losses when productivity is reduced, and quality losses caused by defective products.

2. Setup/adjustment time losses result from downtime and defective products that occur when the production of one 
item ends and the equipment is adjusted to meet the requirements of another item.

3. Idling and minor stop losses occur when production is interrupted by a temporary malfunction or when a machine is idling.

4. Reduced speed losses refer to the difference between the equipment design speed and the actual operating speed.

5 . Reduced yield occurs during the early stage of production from machine startup stabilization.

6. Quality defects and rework are losses in quality caused by malfunctioning production equipment. [2]

$\mathrm{OEE}$ is equal to the multiplication of the three main bases for the main six big losses: 1. Availability indicates the problem which caused by downtime losses. 2. Performance indicates the losses caused by speed losses and 3. Quality indicates the scrap and rework losses.

$\mathrm{OEE}=$ Availability $\mathrm{x}$ Performance rate $\mathrm{x}$ Quality rate[3]

\section{PROBLEM DEFINITION}

Barrel manufacturing process includes

- Pre-Honing

- $\quad$ Profile Grinding

- Deburring

- Final Lapping

- Durr

- Inspection

- Top Face Grinding

Out of these processes, Pre-honing was found to be the bottleneck process. It was analyzed that the OEE of the Prehoning machine line which consisted of 12 machines was $70 \%$ on an average. The delivery takt line was very close to the customer takt line indicating less production as compared to the other processes. Hence there was a requirement for improvement in the line to overcome the problem.

\section{METHODOLOGY}

Shop floor management cycle is a tool developed by Bosch to improve the OEE in the bottleneck process and hence the productivity. The SFMC approach consists of:

- Takt time chart

- Hourly Monitoring Sheets

- OEE Tracking Sheets

- Pareto of losses

- Problem Solving Sheet

- PDCA Sheet

$\bullet$

\subsection{Takt time chart}

Takt time chart is used to satisfy the customer requirement on time. Using the takt time chart the bottle neck processes can be identified. Delivery takt, customer takt and line takt can be visualized. OEE improvement is done in the Honing process as honing is one of the processes in the barrel machining flow having highest delivery takt.

\subsection{Hourly Monitoring Sheet}

According to the Takt Time chart it has been identified that the Pre-Honing machine line is the bottleneck. Hourly monitoring sheet is used on a daily basis to track the rate of production every hour along with the specific losses faced. It is a pre-cursor to the OEE monitoring data-sheet.

The hourly monitoring sheet is designed accordingly to enter the number of parts produced per hour and the cumulative count of the parts from the CNC screen. The target to be met every hour is calculated according to the cycle-time and is mentioned alongside for every hour. There is a specific loss code assigned to every loss occurring during the process of honing which is mentioned at the top of the sheet. Hence if any disruption occurs, the time consumed for every loss is noted down under the particular loss code by the operator working every shift.

\subsection{OEE with Losses}

Total availablity $=24$ hours a day or 1440 minutes a day

Planned run time $=$ total availability $-($ planned downtime planned maintenance).

Planned downtime: [hours or minutes] Periods officially considered in planning. If break times change these must be recorded, either manually or via a mechanical data recording system.

Planned maintenance: [hours or minutes] Within the planned downtime, the planned maintenance is carried out, so that it does not affect the OEE (if the planned maintenance takes place within a period that is otherwise used for production [e.g. 18-shift model], this period must be deducted from the planned run time)

Net operating time $=$ planned run time - availability losses

Availability losses: [hours or minutes] are recorded by the operating personnel/foreman according to pre-determined categories, or by a mechanical data recording system, e.g. tooling, adjusting, tool change, startup losses, unplanned maintenance, malfunctions $>5 \mathrm{~min}$., lack of staff or materials.

Gross production time $=$ net operating time - performance losses

Performance losses: Short downtimes, idle time, longer cycle time. $\breve{S}$

Net production time $=$ gross production time - quality losses $\breve{\mathrm{S}}$

Net production time $=$ good pieces $\mathrm{x}$ technical cycle time (the number of good parts is derived from delivery reports.)

Technical cycle time - if machine cycle time is limited: cycle time of the slowest station (without technical distribution time). 
Calculation rules: The authoritative cycle time is the one at which the facility was procured or that was planned for it. (wear, slow cylinders, etc. should not be counted).

If improvements have been carried out, resulting in lower cycle time (below the planned cycle time), the improved cycle time should be used for the calculation.
Quality losses = bad parts * technical cycle time

They are calculated on the basis of waste/rework or of startup losses with the help of technical cycle time

The daily monitoring of OEE and the losses for machine 6813 for the month of January and February is obtained as follows:

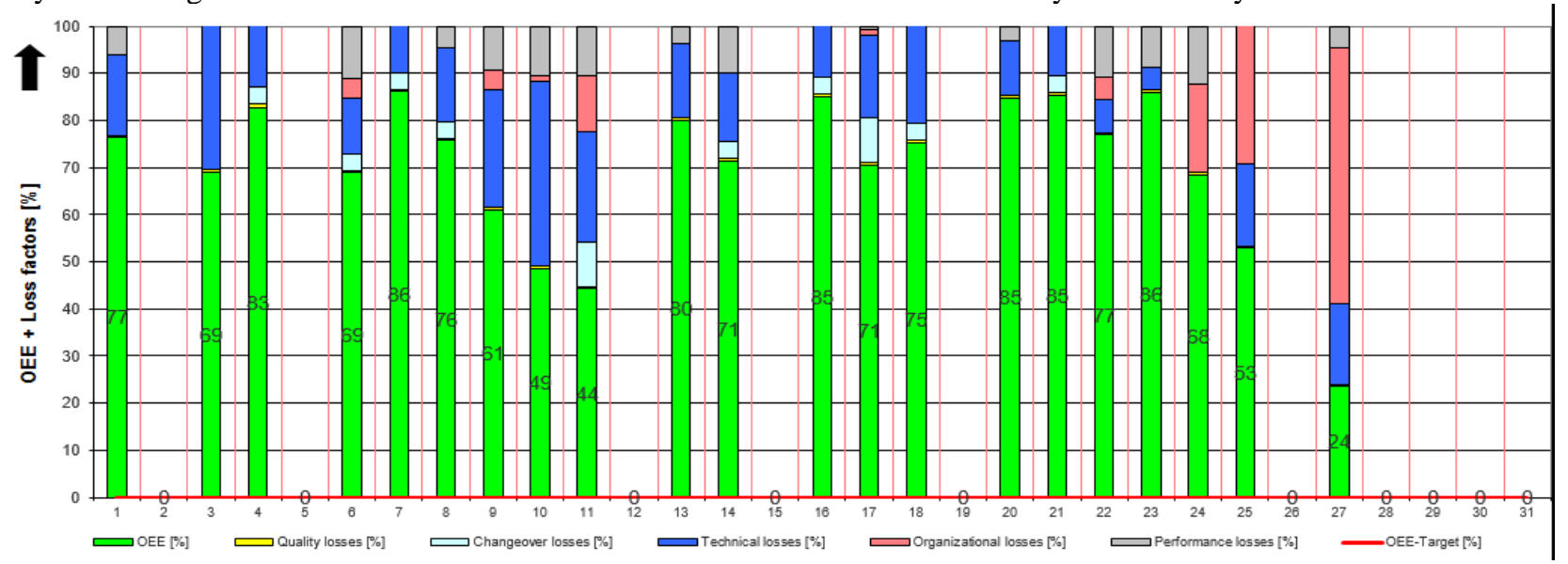

OEE monitoring for January 6813

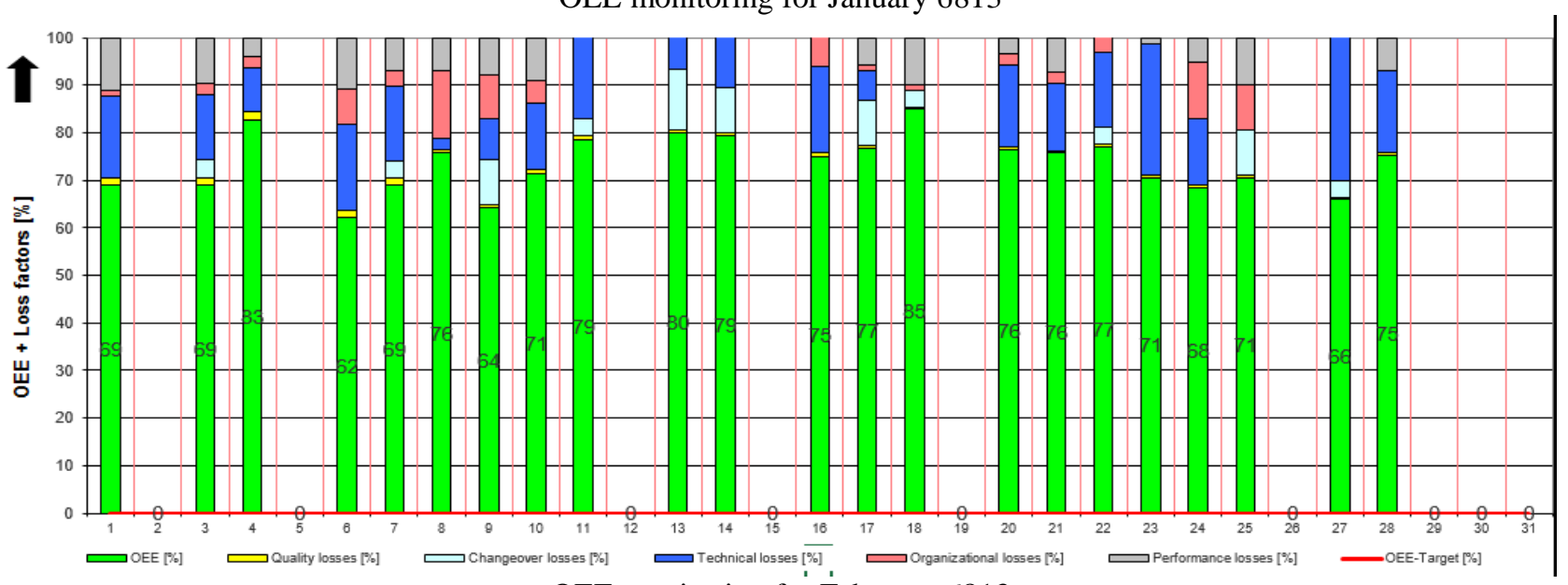

OEE monitoring for February 6813

The daily monitoring of OEE and the losses for machine 6813 for the month of April is obtained as follows:

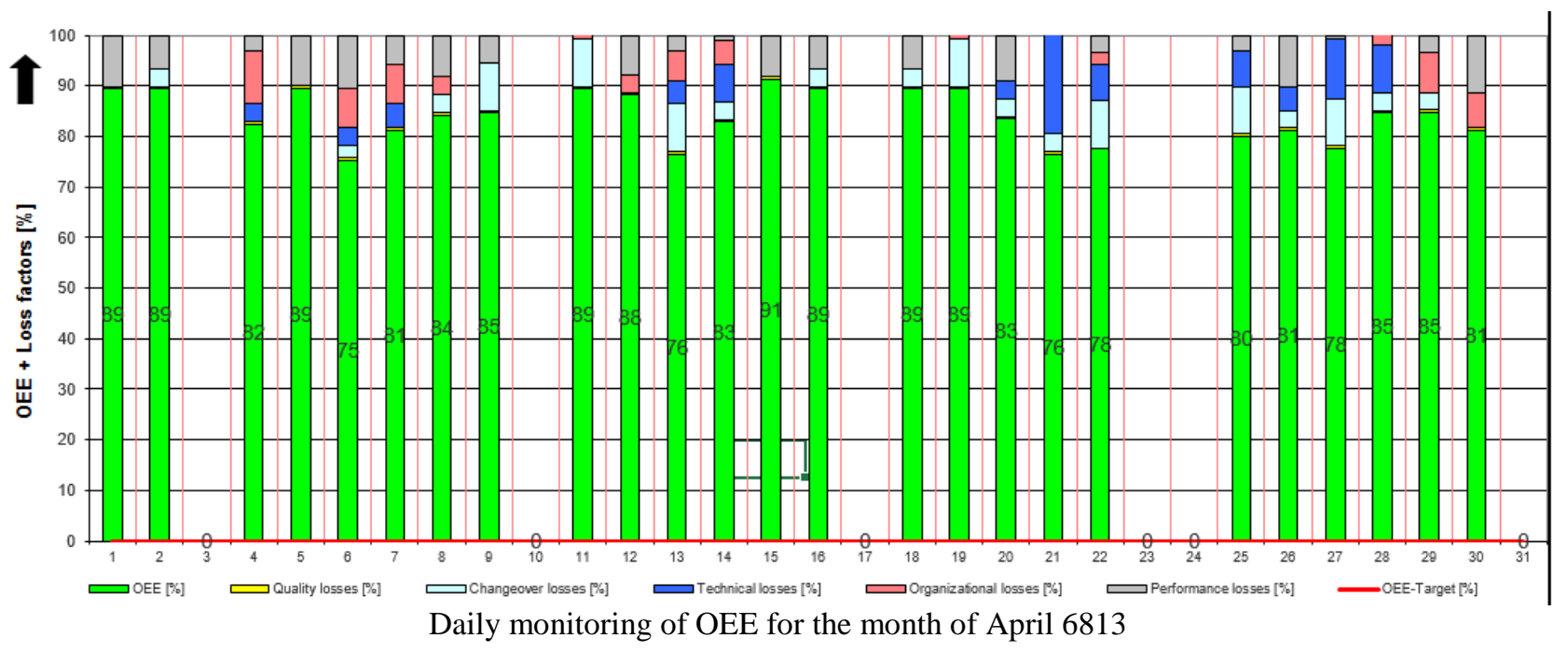




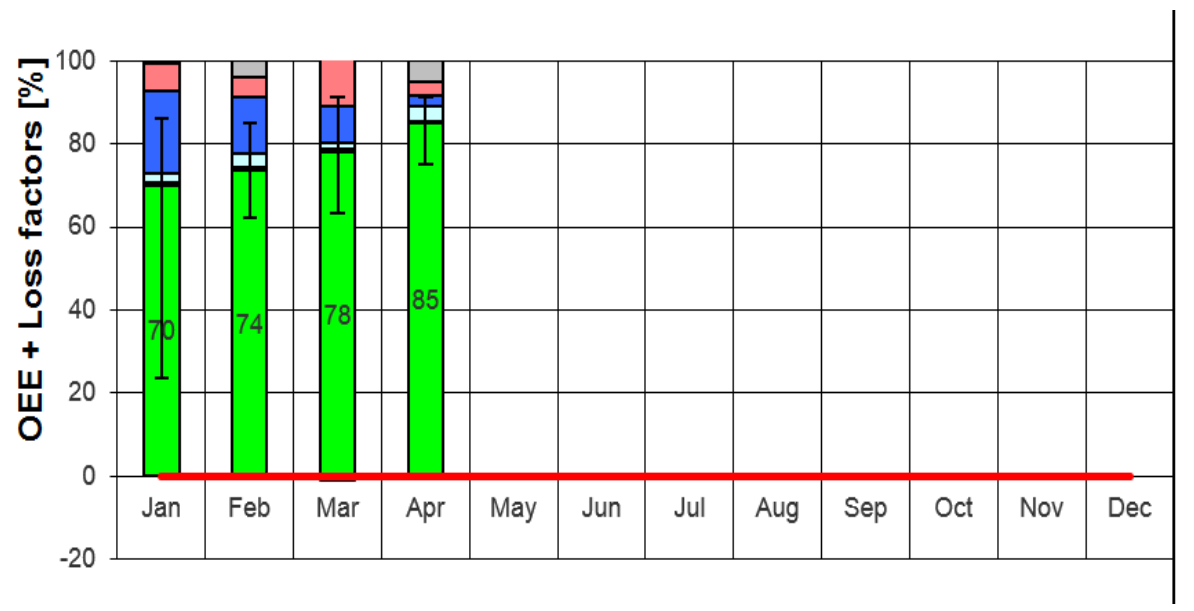

Monthly monitoring of OEE for the month of April 6813

\subsection{Pareto of Losses}

From the Pareto sheet for 6813 , the top five losses of the given period of time is identified. For the month of January, the top five losses were identified as

1. Spindle problems $-6.8 \%$

2. Part Clamping Pump Problems $-4.1 \%$

3. Absenteeism $-3.4 \%$

4. Measuring and Gauging Problems $-2.9 \%$

5. Out pass $-2.7 \%$
From this graph, Spindle problems were identified as the problem causing maximum losses. However on analysis it was concluded that the spindle problems were caused due to the Part clamping pump problem and hence this problem was chosen to be worked upon. On tackling the part clamping problem, both the part clamping problem as well as the spindle problem could be eliminated.

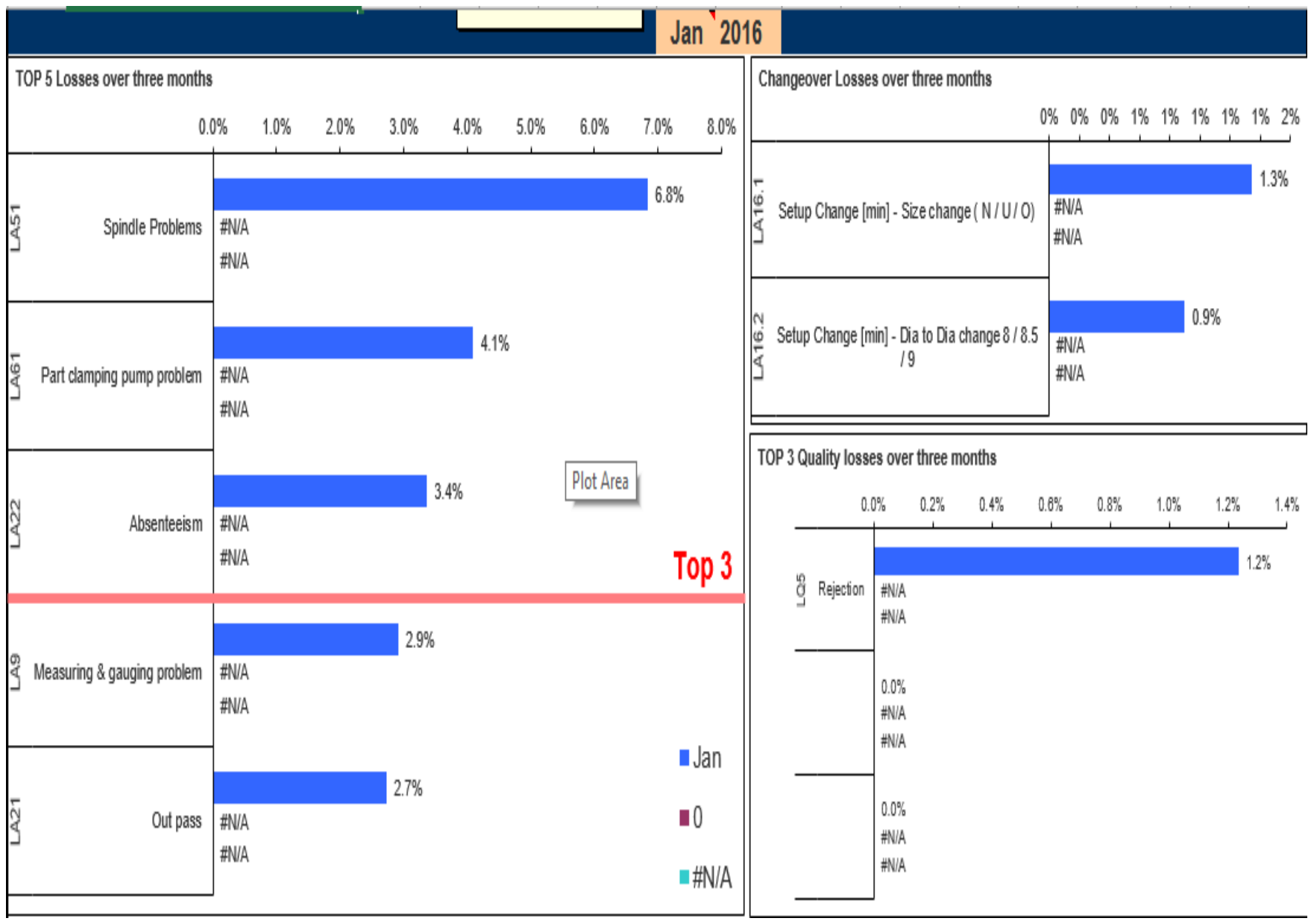




\subsection{Problem Solving Sheet}

Problem solving is one of the most important skills for success in the workplace. The ability to identify a problem, evaluate all of the relevant factors and develop a good solution is essential. Whether you are experiencing conflict with a co-worker, dealing with multiple tasks that need to be prioritized, or trying to track a shipment that hasn't arrived, problem solving plays a vital role.

This tool is designed to help practice and improve problemsolving skills. It has four sections:

Section 1: Problem Description

Section 2: Problem Solving Technique

Section 3: Five Whys

Section 4: Actions

\subsubsection{PSS Analysis}

Machine 6813:

Section 1: Problem Description

Based on the Pareto analysis the top three problems were identified to be part clamping problem, spindle problem and absenteeism. The highest of these losses was the spindle problem. But it was identified that the spindle problem could be resolved by eliminating the part clamping problem which came up to $4.1 \%$ of the total losses. Hence, the Part Clamping problem became the subject of study.

\section{Section 2: Problem-solving technique \\ Ishikawa Diagram (Cause and Effect Diagram)}

Causes are usually grouped into major categories to identify the sources of variation. The categories typically included:

Man: Anyone involved with the process

It was seen that the maintenance team wasn't efficient. Also, regular maintenance wasn't being carried out.

Methods: How the process is performed and the specific requirements for doing it, such as policies, procedures, rules, regulations and laws

Same oil was being used as a cutting fluid and for fixture clamping.

Machines: Any equipment, computers, tools, etc. required to accomplish the job

There was mug collected in the hydraulic floor.

MAZ problem.

MCB tripping.

Materials: Raw materials, parts, pens, paper, etc. used to produce the final product

Fixture NOT OK.

Rubber sleeve quality issues.

Environment: The conditions, such as location, time, temperature, and culture in which the process operates

Increase in the temperature of the oil.

\section{5-Why Technique}

The primary goal of the technique is to determine the root cause of a defect or problem by repeating the question "Why?" Each question forms the basis of the next question. The "5" in the name derives from an empirical observation on the number of iterations typically required to resolve the problem.
Not all problems have a single root cause. If one wishes to uncover multiple root causes, the method must be repeated asking a different sequence of questions each time.

The method provides no hard and fast rules about what lines of questions to explore, or how long to continue the search for additional root causes. Thus, even when the method is closely followed, the outcome still depends upon the knowledge and persistence of the people involved.

\section{Root cause 1: Mug not separated from the oil}

Why? Filtration not effective.

Why? Big size grains weren't separated.

Why? Grains tore through the filter paper.

Why? Separator wasn't installed.

Root cause 2: Fixture

Why?

No proper bottom plate

Why?

Drawings not being followed.

Why?

New supplier

Root cause 3: Rubber Sleeve

Why?

Getting punctured.

Why?

Big size grains

Why?

Same oil used for lubrication and clamping

Why?

Separator not installed

Root cause: There is no formal process for submitting job postings to human resources.

Once you have determined the root cause(s) of the problem, take the appropriate steps to resolve the issue.

Section 4: Actions

Immediate actions: Tank cleaning was carried out and thorough cleaning of the oil was done.

Corrective actions: Magnetic mist collector was installed. The root causes are identified and their solutions derived at the end of this sheet. 
Machine no 6813:

\section{Problem solving sheet}

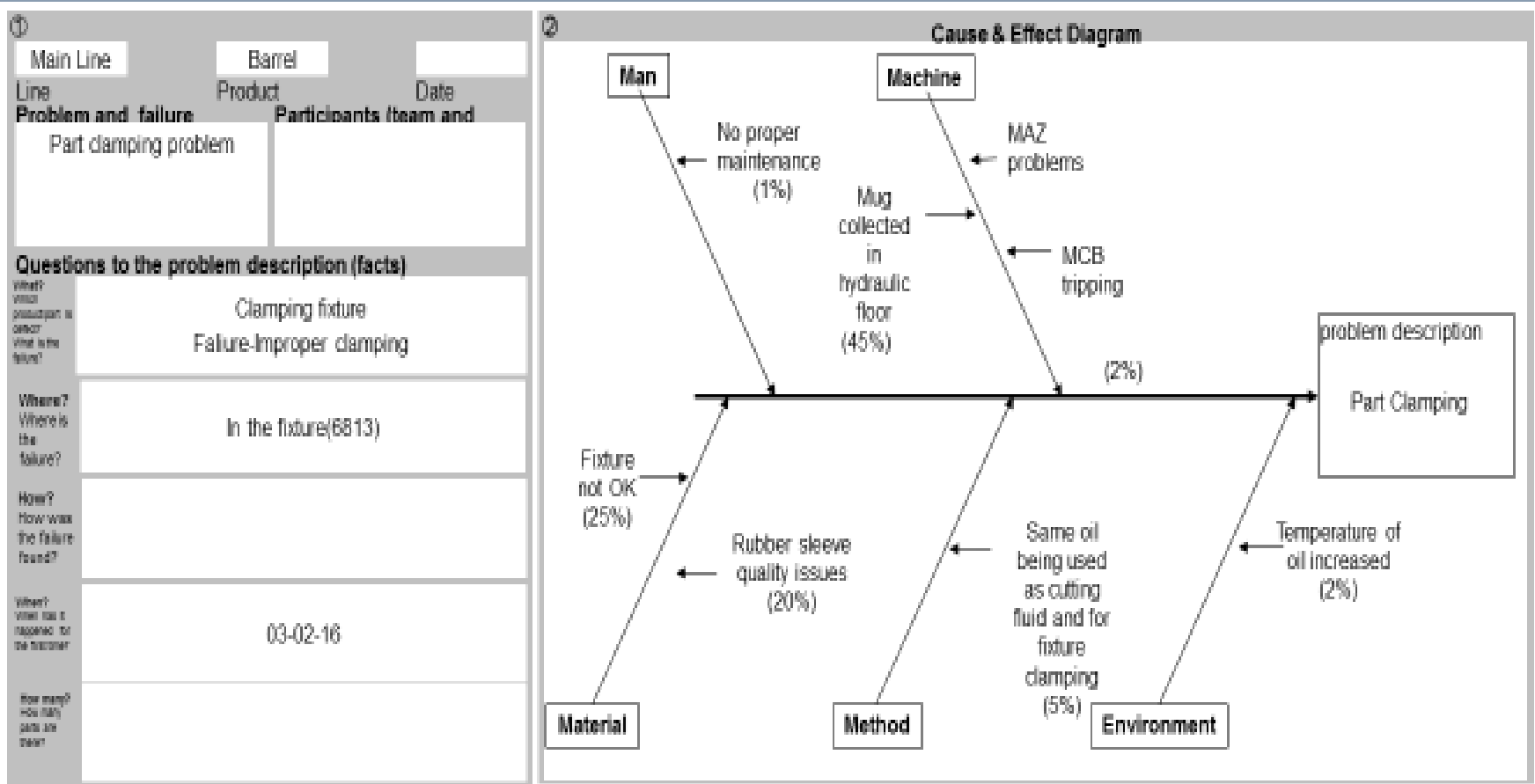

\begin{tabular}{|c|c|c|c|c|}
\hline \multicolumn{5}{|c|}{ Actions } \\
\hline cost & Immediate actions & Navooth & 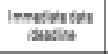 & Stats \\
\hline 1. & Tank Clearing & & & \\
\hline 2 & Oil deaning & & & \\
\hline & & & & \\
\hline & & & & \\
\hline Mosit & Corrective sctions (for sustanable problem solition) & Nascooth & Imentingen & suso \\
\hline u & Magnetic Nist collector installod & & & \\
\hline & & & & \\
\hline & & & & \\
\hline & & & & \\
\hline & & & & \\
\hline
\end{tabular}

\begin{tabular}{|c|c|c|c|}
\hline \multirow[t]{2}{*}{3} & \multicolumn{3}{|c|}{ 6x Why (three main root causes) } \\
\hline & 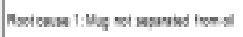 & Noteswa intantor & 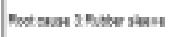 \\
\hline 1. $m a n$ & $\begin{array}{l}\text { Filtration not } \\
\text { effective }\end{array}$ & $\begin{array}{l}\text { No proper bottom } \\
\text { plate }\end{array}$ & $\begin{array}{l}\text { Getting } \\
\text { pundured }\end{array}$ \\
\hline $2 m n n$ & $\begin{array}{l}\text { Big sized grains } \\
\text { werent } \\
\text { separated }\end{array}$ & $\begin{array}{l}\text { Drawings nat } \\
\text { being folowed }\end{array}$ & $\begin{array}{l}\text { Bigsized } \\
\text { grains }\end{array}$ \\
\hline $3 \mathrm{man}$ & $\begin{array}{l}\text { Grains tore } \\
\text { through the } \\
\text { filter }\end{array}$ & New suppler & $\begin{array}{l}\text { Some ail } \\
\text { used for } \\
\text { lutrication } \\
\text { and clamging }\end{array}$ \\
\hline 4 wan & $\begin{array}{l}\text { Separator } \\
\text { wasit } \\
\text { instaled }\end{array}$ & & $\begin{array}{c}\text { Separator } \\
\text { wasn't installed }\end{array}$ \\
\hline s.man & & & \\
\hline
\end{tabular}

DSIBPS-V1.0 (21-04-2006) 
Machine no. 11512

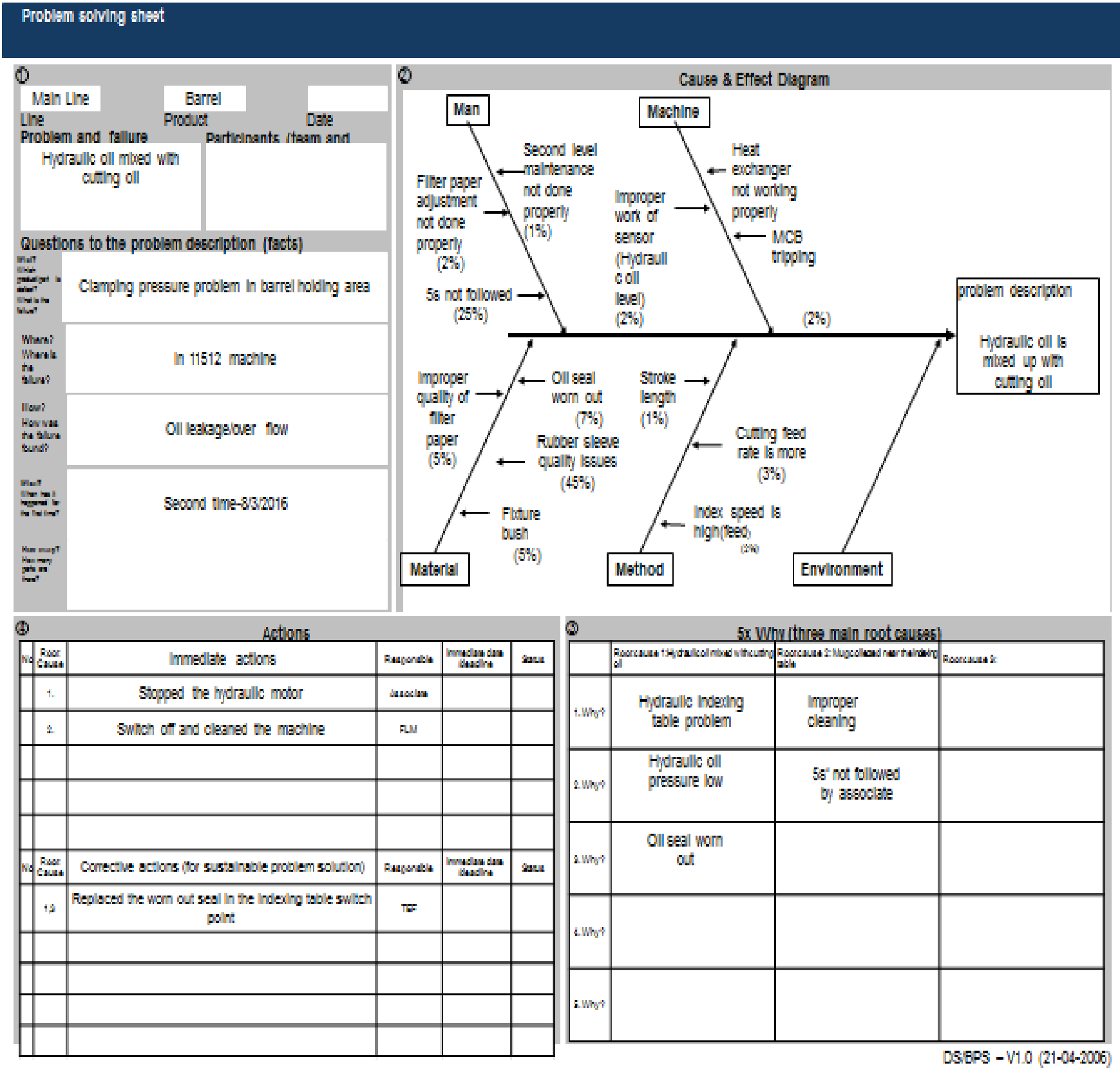

\subsection{PDCA Sheet}

The PDCA technique is focused on continuous improvement. Once the root causes are identified using the Problem Solving Sheet, implementation of the solutions is done with the help of the PDCA cycle. The measurement of results closes the PDCA circle, gives information about the quality and implementation of the measures and is input for further improvements.

\begin{tabular}{|l|ll|}
\hline \multicolumn{3}{|l|}{ Plan, Do, Check, Act (PDCA) technique } \\
\hline Plan & $\bullet$ & $\begin{array}{l}\text { Identify a process or situation that needs to be improved. } \\
\text { Develop an action plan (solutions) to address it }\end{array}$ \\
\hline Do & $\bullet$ & Carry out the action plan. \\
\hline Check & $\bullet$ & Study the results of carrying out the action plan. What did you learn? Were improvements made? \\
\hline Act & $\begin{array}{l}\text { Make a decision. If the action plan was successful, use it to plan future improvements. If it was not successful, } \\
\text { repeat the cycle and develop a new approach. }\end{array}$ \\
\hline
\end{tabular}


Measures or plan delegation: Machine no. 6813

Solution for root cause 1:

Magnetic mist collector installed (Filtration)

Solution for root cause 2:

Inspection report was expected from the supplier.

Solution for root cause 3:

Magnetic mist collector was installed (Rubber sleeve)

\section{PDCA for Machine no. 6813}

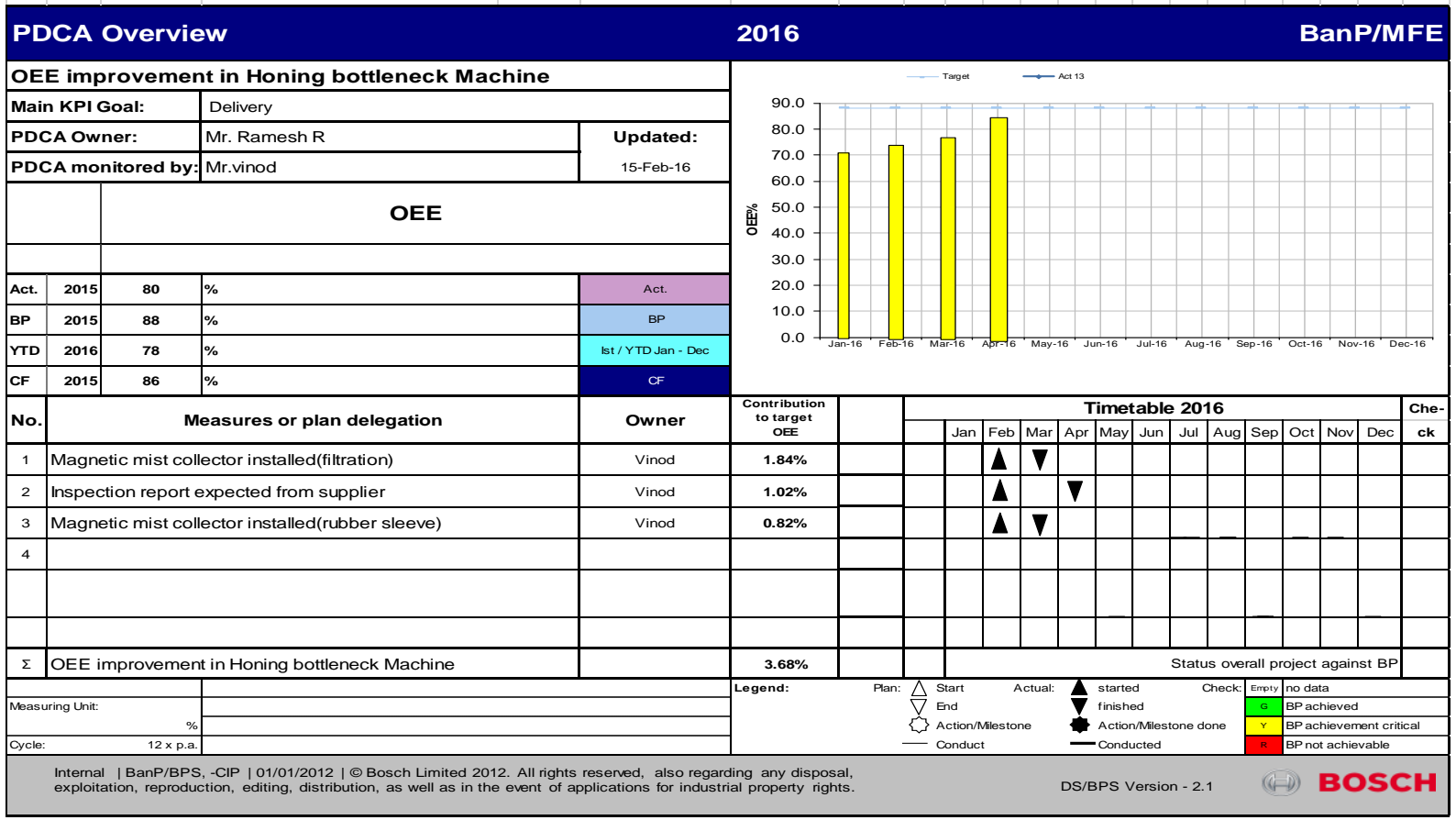

On completion of the SFMC cycle, the losses that were identified in machines 6813

\section{Machine 6813}

\begin{tabular}{|l|l|l|l|l|}
\hline Machine no & \multirow{4}{*}{ Months } & \multicolumn{3}{|l|}{ Losses } \\
\cline { 2 - 5 } & & Availability & Performance & Quality \\
\cline { 2 - 5 } & January & 29 & 7.61 & 0.47 \\
\cline { 2 - 5 } 6813 & February & 22.45 & 7.28 & 0.5 \\
\cline { 2 - 5 } & March & 21.75 & 6.43 & 0.5 \\
\cline { 2 - 5 } & April & 9 & 6.43 & 0.43 \\
\hline
\end{tabular}

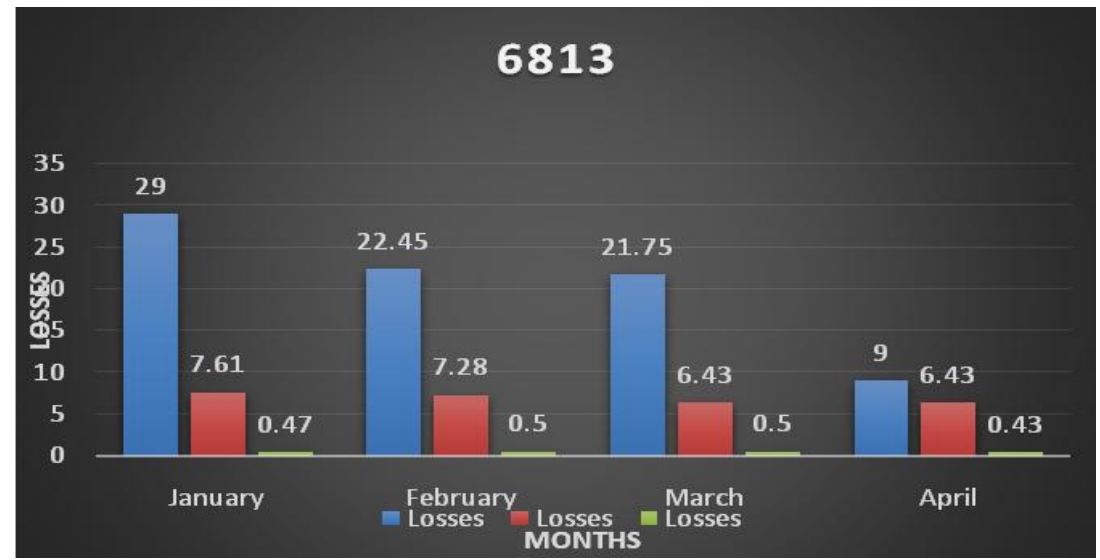




\section{RESULTS AND CONCLUSION}

Using the SFMC approach, the problem area was identified as explained earlier. The related issues and their causes were scrutinized and their solutions derived. Using this methodology, the OEE of the Pre-Honing machine line, consisting of 12 machines in total, was improved from $70 \%$ in January to $84 \%$ in April. The SFMC approach is a derivative of Total Productive Maintenece. It is an on-going procedure to keep the machines and equipment in good working condition. By using this approach, which consisted of various tools such as Line balancing, Hourly Monitoring Sheets, OEE tracking sheets, Pareto losses, Problem solving sheets and PDCA cycles the resons for the reduced OEE in the bottleneck machines were isolated to be worked on.
During the period of study, January to April, the problems were worked upon thereby improving the OEE of the bottleneck machines and hence the average OEE of the entire line. The kinds of losses that take place during manufacturing were classified into availability, performance and quality losses and calculations for the same were made. The root cause for the problem identified in the pareto analysis was obtained using the Ishikawa diagram and 5 Why analysis, after which the PDCA cycle helped in implementation of the solution o rectify the problem.

The data is represented in a graphical form for the month of January:

\begin{tabular}{|l|l|l|l|l|l|}
\hline S1. No. & Machine no. & $\begin{array}{l}\text { Availability loss } \\
(\%)\end{array}$ & Performance loss $(\%)$ & Quality loss $(\%)$ & OEE (\%) \\
\hline 1 & 6813 & 31.95 & 7.61 & 0.47 & 70 \\
2 & 11512 & 19 & 6.31 & 0.47 & 68 \\
3 & 65124 & 20 & 7.5 & 0.5 & 81 \\
4 & 6952 & 19 & 7.64 & 0.623 & 79 \\
5 & 6953 & 20 & 7.56 & 0.476 & 81 \\
6 & 7657 & 23 & 6.94 & 0.58 & 79 \\
7 & 7753 & 22 & 5.95 & 0.56 & 77 \\
8 & 11396 & 25 & 7.9 & 0.57 & 76 \\
9 & 53002 & 20 & 5.86 & 0.5 & 74 \\
10 & 53003 & 22 & 7.03 & 0.5 & 79 \\
11 & 53016 & 25 & 6.62 & 0.5 & 76 \\
12 & 60140 & 6.03 & 0.5 & 74 \\
\hline
\end{tabular}

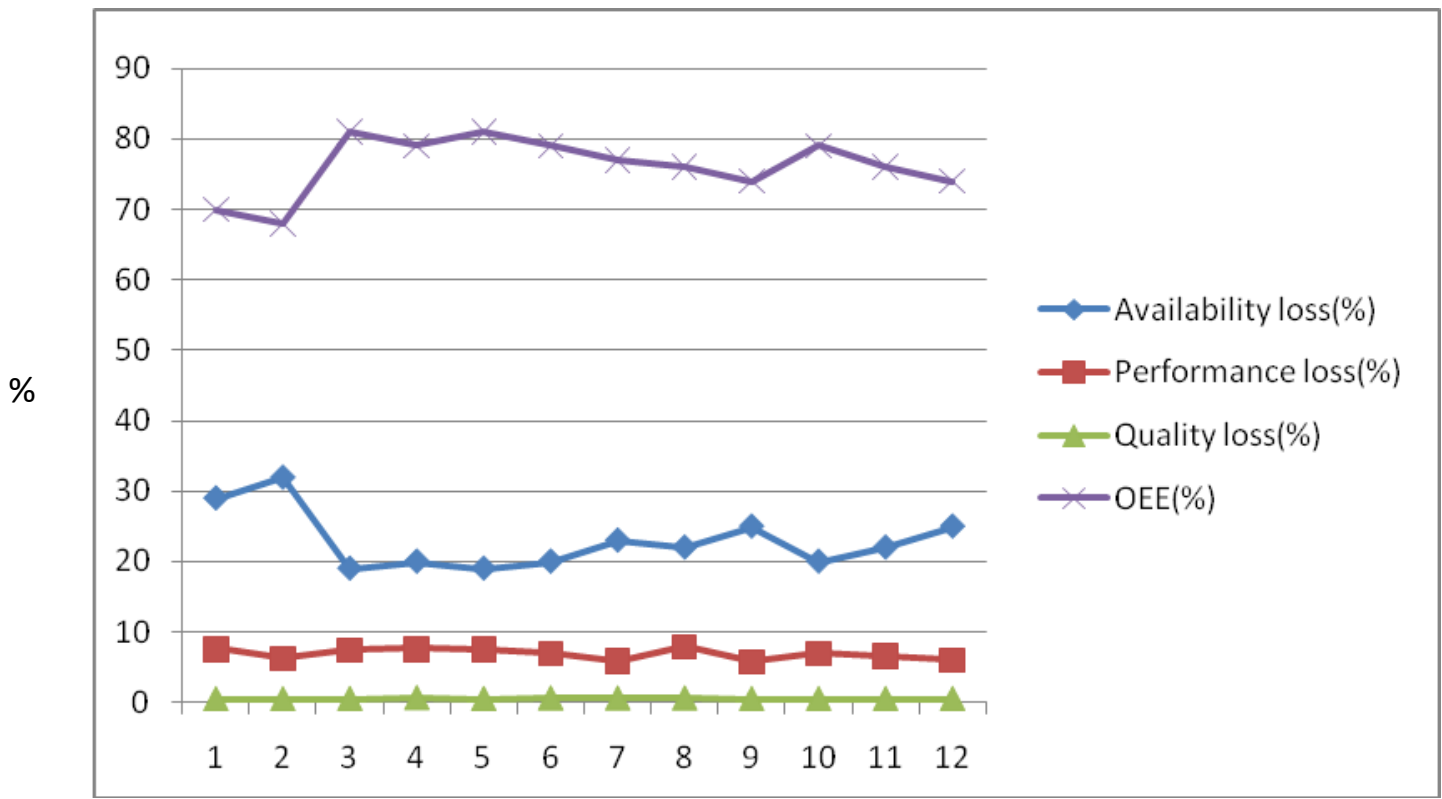

Machine no. 
The data is represented in a graphical form for the month of April:

\begin{tabular}{|l|l|l|l|l|l|}
\hline Sl No. & Machine no. & Availability loss(\%) & Performance loss(\%) & Quality loss(\%) & OEE(\%) \\
\hline 1 & 6813 & 9 & 6.43 & 0.43 & 85 \\
2 & 11512 & 9 & 6.7 & 0.7 & 84 \\
3 & 65124 & 11 & 7.1 & 0.5 & 82 \\
4 & 6952 & 10 & 8.01 & 0.5 & 83 \\
5 & 6953 & 11 & 7.11 & 0.5 & 82 \\
6 & 7657 & 11 & 7.41 & 0.6 & 82 \\
7 & 7753 & 14 & 6.8 & 0.5 & 78 \\
8 & 11396 & 14 & 6.9 & 0.4 & 78 \\
9 & 53002 & 13.7 & 8.22 & 0.6 & 77 \\
10 & 53003 & 11 & 7.5 & 0.5 & 82 \\
11 & 53016 & 14.1 & 7.6 & 0.5 & 78 \\
12 & 60140 & 15.45 & 7.95 & 0.5 & 79 \\
\hline
\end{tabular}

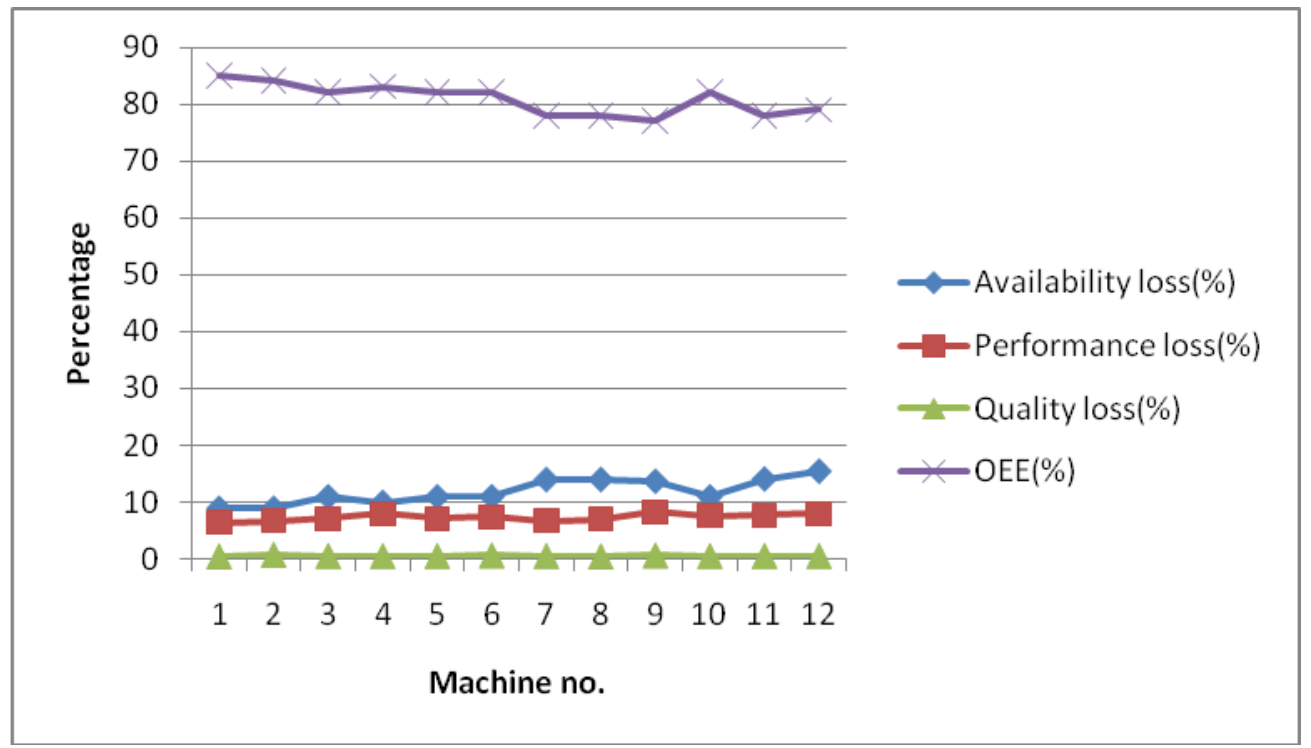

From the above graphs, it can be seen that the OEE has increased for the two bottleneck machines, 6813 and 11512 from the month of January to April.

In conclusion, this project helped us implement practically the concepts of OEE and TPM and gain hands-on experience in the problems faced by a manufacturing plant in the maintenence of machines and equipmenet. By tackling some of these issues the project was beneficial to Bosch Ltd. as the effectiveness of the Pre-Honing line was improved.

\section{Cost Calculation}

As the OEE increases, productivity also increases. Hence, when the OEE is increased to $84 \%$, the number of parts produced during a given period also increases. This is shown in the calculations below:

1 shift $=8$ hours

Break $=55 \mathrm{~min}$
$=60 \times 8-55$

$\mathrm{POT}=8$ hours

$\mathrm{POT}=8 \times 60-55=425 \mathrm{~min}$

Cycle time $/$ piece $=18 \mathrm{sec}$

OEE at $70 \%=425 \times 60 \times 0.7 / 18$

$=991 \mathrm{pcs} / \mathrm{shift}$

OEE at $84 \%=425 \times 60 \times 0.84 / 18$

$=1190 \mathrm{pcs} / \mathrm{shift}$

Increase in number of parts $=1190-991$

$=199 \mathrm{pcs} / \mathrm{shift}$

No. of pieces increased per year/ operator $=199 \times 24 \times 12$ $=57312 \mathrm{pcs} /$ year

No. of pieces for 18 operators $=57,312 \times 18$

$=10,31,616 \mathrm{pcs} /$ year 
Ideal production per operator $=1250 \mathrm{pcs} \times 24 \times 12$

$=3,60,000 \mathrm{pcs} /$ year

Profit $=$ Increase in production/ Ideal production

$=10,31,616 / 360000$

$=2.8 \sim 2$ operators

Cost to company for each operator $\sim 8 \mathrm{LPA}$

Hence, profit made $=2 \times 8=16 \mathrm{LPA}$

As the OEE was increased from $70 \%$ to $84 \%$, the production of the machines also increased. Hence according to the above calculation, the target can be met by 16 workers instead of 18. As there is an excess of two workers, the company can make a profit of 16lakhs per annum.

\section{REFERENCES}

[1] "Bosch, R. Bosch Automotive Handbook", 8/e, Wiley Publishing Company, Hoboken, New jersey, 2004.

[2] J. DE RON and J. E. ROODA, "OEE and equipment effectiveness: an evaluation", Published in the International Journal of Production Research, Vol. 44, No. 23, 1 December 2006, 4987-5003

[3] Osama Taisir R.Almeanazel, “ Total Productive Maintenance Review and Overall Equipment Effectiveness Measurement", Published in the JJMIE Volume 4, Number 4, September 2010 ISSN 19956665 Pages 517 - 522 Jordan Journal of Mechanical and Industrial Engineering

[4] John Konopka, Walt Trybula, "OVERALL EQUIPMENT EFFECTIVENESS (OEE) and COST MEASUREMENT", IEEE

[5] Tom Pomorski, "Managing Overall Equipment Effectiveness [OEE] to Optimize Factory Performance", IEEE

[6] A.J. de Ron and J. E. Rooda, "Equipment Effectiveness: OEE Revisited", IEEE

[7] Robert W. Freck, "Using Overall Equipment Effectiveness (OEE) and the Equipment Improvement Process (EI) to Improve Fab Throughput", IEEE

[8] Panagiotis H. Tsarouhas, "Evaluation of overall equipment effectiveness in the beverage industry: a case study, International Journal of Production Research

[9] S. Fore, L. Zuze, "Improvement of Overall Equipment Effectiveness through Total Productive Maintenance", World Academy of Science, Engineering and Technology International Journal of Mechanical, Aerospace, Industrial, Mechatronic and Manufacturing Engineering Vol:4, No:1, 2010

[10] P. MUCHIRI and L. PINTELON, "Performance measurement using overall equipment effectiveness (OEE): literature review and practical application discussion", International Journal of Production Research,Vol. 46, No. 13, 1 July 2008, 3517-3535

[11] Francesco Zammori, Marcello Braglia and Marco Frosolini, "Stochastic overall equipment effectiveness", International Journal of Production Research Vol. 49, No. 21, 1 November 2011, 64696490 